\title{
Beyond Wild and Tame: Soiot Encounters in a Sentient Landscape. By Alex C. Oehler. 2020. Berghahn Books, New York, NY. 214 pp.
}

\author{
Eva Kotašková ${ }^{*}$ \\ ${ }^{1}$ Department of Sociology, Faculty of Social Studies, Masaryk University, Brno, Czech Republic. \\ *332998@mail.muni.cz
}

Received July 1, 2020

OPENӘACCESS

Accepted September 11, 2020

DOI 10.14237/ebl.11.1.2020.1716

Published September 25, 2020

Copyright (C) 2020 by the author(s); licensee Society of Ethnobiology. This is an open-access article distributed under the terms of the Creative Commons Attribution-NonCommercial 4.0 International Public License (https://creativecommons.org/licenses/by-nc/4.0), which permits non-commercial use, distribution, and reproduction in any medium, provided the original author and source are credited.

The dichotomy of wild and tame has been a wideranging topic of many academic discussions across disciplines. Although Alex C. Oehler does not explicitly discuss the many anthropological theories about wildness and tameness, he provides interesting insight into these discussions in his ethnography of relations emerging within human-animal encounters in Soiot region of south Siberia.

Beyond Wild and Tame is an ethnography of Soiot communities with a focus mainly on the Oka-Soiots during 2012, 2014, and 2018. Together with comprehensive archival research on Soiot history, archaeology and previous (scarce) ethnographic work, Oehler gives a complex account of Soiot encounters with various animals.

The author's focus on relations is inspired mainly by Tim Ingold and von Uexküll's concept of "Umwelt" (perspective). As a reaction to predominant focus on reindeers in Siberian ethnographies, Oehler chose a frame of "multispecies ethnography." In this book, multispecies ethnography refers to the author's focus on people (Oka-Soiots) and multiple species of animals (reindeers, yaks, horses, and wolves). When writing about animals, Oehler is focused on Soiots' perspectives rather than making claims regarding the intentions of animals himself, but at the same time, he references genetics, evolution, morphology, and animal population studies to give a context for Soiot human-animal relations.

The structure of the book is clear and offers a complex illustration of domestication and wildness with a focus on both humans and animals. In regard to the question of domestication, Oehler first describes the Oka-Soiot household, which in Soiot cosmology is a mirror image of spirit households of the taiga (Chapter 1). What is domestic for humans is a game for spirits and vice versa. In Soiot perspective, the "domestic" is an outcome of negotiation within the environment, rather than an outcome of solely human actions. Regarding spirituality and cosmology, Chapter 2 describes the historical influences of shamanism and Buddhism, resulting in Soiot herderhunters' adaptation of both perspectives and contextual movement between shamanic and Buddhist perceptions of the landscape according to the needs of people and animals.

Chapter 3 contrasts Soiot and Tofa reindeer herding practices and relations emerging in the presence of other species in both human and spirit households. Reindeer herding, strongly influenced by political influences of the past, remains a strong symbol of Soiot identity. This chapter emphasizes historical variations in the dynamics between humans and reindeer, as well as seasonal flexibility of households. For the Soiots, to maintain mutual relations with reindeer is to be flexible throughout the seasons but also to have the ability to see from the viewpoint of the animal.

While reindeers are interpreted as symbols of the past, the yak is rather symbolic of the present because of its hybrid character (Chapter 4). Oka is the only place in which Indigenous residents took up yak breeding, and with a focus on history and archaeology, Oehler explains why. The roots of yak herding together with its symbolic status are traced back to Mongolia and further into Tibet. Chapter 4 further discusses the historical influence of Mongolian 
dairy cattle and its effect on nomadic movement resulting in an increasing sedentary lifestyle and implementation of hybrid breeding techniques.

In comparison to other species such as reindeer or yak, the features associated with wildness can also be seen as desirable in human-horse relations, as discussed in Chapter 5. All three species are valued for their "wild" ability to forage for themselves in winter. Therefore, techniques such as castration are not only intended to increase docility in animals but are a way to foster fierceness and self-reliance in select herd animals. However, this is often not a matter of a wild-tame dichotomy but is understood in terms of negotiation or management of human and animal intentions and will, which changes according to seasonal fluctuation of proximity between humans and horses. The chapter also focuses on material implements such as ropes, corrals, horseshoes, or saddles as part of communicative devices between humans and non-humans. While one needs to account for the animal intention or resistance, such devices are, ultimately, co-producing the sociality of the animals.

Relations with wolves, described in Chapter 6, carry both admiration and hate. Wolves are seen at times as a species inherently autonomous and at times as emissaries of a spirit master. Either way, they are known in Oka primarily as good learners who are able to learn from careful observation and develop their capacity to predict another's intentions or movements. Hidden intent, it seems, stood at the center of wolfhuman interactions in Oka and Chapter 6 shows how both humans and wolfs design to conceal intent through human-built traps with wolf-designed dens.

Although Beyond Wild and Tame does not aim to be "classic ethnography" focused on the life of the Soiots, the reader certainly gains insight into their lifeways throughout the book. With a focus on human -animal relations, the author contextualizes OkaSoiots in the surrounding communities of the whole Soiot region and in the history of the regions back to $300 \mathrm{BC}$ with influence from Mongolia or Turkey and other historical-political influences. The book provides an extensive insight for scholars interested in the south Siberian area (especially considering the lack of archaeology and anthropology of Oka-Soiots) across disciplines. The language is rather descriptive, and mostly looks to history, archaeology, or genetics, rather than to anthropological theories. Anthropological-theoretical discussions and interpretations of the Soiot human-animal relations are mainly in the conclusion. Beyond Wild and Tame is a detailed illustration of how diverse current and past humannonhuman relations can be and of the diversity in form of wildness and tameness. 